\title{
Exacerbation of Cushing's syndrome during pregnancy: stimulation of a cortisol-secreting adrenocortical adenoma by ACTH originating from the foeto-placental unit
}

\author{
Matthieu St-Jean*, Jessica MacKenzie-Feder*, Isabelle Bourdeau and André Lacroix \\ Division of Endocrinology, Department of Medicine and Research Center, Centre Hospitalier Universitaire de \\ Montréal, Montréal, Québec, Canada \\ *(M St-Jean and J MacKenzie-Feder contributed equally to this work)
}

Correspondence

should be addressed

to A Lacroix

Email

andre.lacroix@umontreal.ca

\section{Summary}

A 29-year-old G4A3 woman presented at 25 weeks of pregnancy with progressive signs of Cushing's syndrome (CS), gestational diabetes requiring insulin and hypertension. A $3.4 \times 3.3 \mathrm{~cm}$ right adrenal adenoma was identified during abdominal ultrasound imaging for nephrolithiasis. Investigation revealed elevated levels of plasma cortisol, $24 \mathrm{~h}$ urinary free cortisol (UFC) and late-night salivary cortisol (LNSC). Serum ACTH levels were not fully suppressed (4 and 5 pmol/L ( $N$ : 2-11)). One month post-partum, CS regressed, 24-h UFC had normalised while ACTH levels were now less than $2 \mathrm{pmol} / \mathrm{L}$; however, dexamethasone failed to suppress cortisol levels. Tests performed in vivo 6 weeks post-partum to identify aberrant hormone receptors showed no cortisol stimulation by various tests (including $300 \mathrm{IU}$ hLH i.v.) except after administration of $250 \mu \mathrm{g}$ i.v. Cosyntropin 1-24. Right adrenalectomy demonstrated an adrenocortical adenoma and atrophy of adjacent cortex. Quantitative RT-PCR analysis of the adenoma revealed the presence of ACTH (MC2) receptor mRNA, while LHCG receptor mRNA was almost undetectable. This case reveals that CS exacerbation in the context of pregnancy can result from the placental-derived ACTH stimulation of MC2 receptors on the adrenocortical adenoma. Possible contribution of other placental-derived factors such as oestrogens, $\mathrm{CRH}$ or $\mathrm{CRH}$-like peptides cannot be ruled out.

\section{Learning points:}

- Diagnosis of Cushing's syndrome during pregnancy is complicated by several physiological alterations in hypothalamic-pituitary-adrenal axis regulation occurring in normal pregnancy.

- Cushing's syndrome (CS) exacerbation during pregnancy can be associated with aberrant expression of LHCG receptor on primary adrenocortical tumour or hyperplasia in some cases, but not in this patient.

- Placental-derived ACTH, which is not subject to glucocorticoid negative feedback, stimulated cortisol secretion from this adrenal adenoma causing transient CS exacerbation during pregnancy.

- Following delivery and tumour removal, suppression of HPA axis can require several months to recover and requires glucocorticoid replacement therapy. 


\section{Background}

Cushing's syndrome (CS) rarely occurs during pregnancy as increased levels of cortisol induces ovulatory dysfunction and relative infertility (1). Cushing's disease (CD) is responsible for $70 \%$ of CS cases in non-pregnant patients (1); during pregnancy, primary adrenal adenoma, adrenocortical carcinoma, bilateral macronodular adrenal hyperplasia (BMAH) or primary pigmented nodular adrenal disease (PPNAD) represent $50-60 \%$ of CS cases $(1,2)$. It was suggested that androgen excess associated with CD suppresses more efficiently ovulation compared to primary adrenal lesions that produce less androgen secretion $(1,2)$.

CS is difficult to diagnose during pregnancy because of the overlap in the clinical features associated with CS and normal pregnancy. Also, placental-driven alterations in hypothalamic-pituitary-adrenal physiology during pregnancy complicate the diagnostic approach (2). It is primordial to diagnose CS during pregnancy because it is associated with significant materno-foetal complications and its therapy decreases foetal loss and potentially maternal morbidity (1). Herein, we describe a patient with CS exacerbation during pregnancy that was secondary to a different mechanism than previously reported in cases of pregnancy-induced or exacerbated CS.

\section{Case presentation}

A 29-year-old G4A3 woman was found at 25 weeks of pregnancy to have a $3.4 \times 3.3 \mathrm{~cm}$ right adrenal mass on abdominal ultrasound performed for acute nephrolithiasis. Starting 1 year before her pregnancy, she had only noticed modest weight gain, fatigue and lack of concentration. From 20 weeks of gestation, she noted purple stretch marks on her abdomen, facial rounding, supra-clavicular fat accumulation, dorsal fat pad, mild bilateral pedal oedema, mild proximal leg weakness associated with sciatica. She gained 32 pounds during her pregnancy. Her fasting blood glucose in the first trimester was $5.1 \mathrm{mmol} / \mathrm{L}$, but she developed gestational diabetes during the second trimester and required $100 \mathrm{U}$ of insulin/day by 34 -week gestation. She also developed gestational hypertension at 36-week gestation. At 25-week gestation, investigations revealed loss of diurnal plasma cortisol rhythm but only a slight increase in 24-h UFC. However, at 31 weeks of gestation, she had overt elevation of late-night salivary cortisol (LNSC) and 24-h UFC (Table 1). Corresponding plasma ACTH levels were not fully suppressed despite an 8.6-fold elevation of UFC (Table 1). Delivery was induced at 37-week gestation because of hypertension and intrauterine growth restriction. She delivered vaginally a $2.51 \mathrm{~kg}$ female baby. The baby required assisted positive pressure ventilation for 2 min immediately after birth and was found to have low morning serum cortisol values $<80 \mathrm{nmol} / \mathrm{L}$ and hypocalcaemia-requiring therapy with prednisolone $0.1 \mathrm{mg}$ i.v. twice daily and calcium supplements for several days. The child is now a healthy 3-year old.

One month post-partum, CS signs had regressed considerably in the mother with reduced appetite and normalisation of glucose levels without any therapy. Her 24-h UFC had normalised (107 nmol/day, Normal value $(\mathrm{NV})<120)$ with corresponding suppressed ACTH of $1.4 \mathrm{pmol} / \mathrm{L}$ (NV: 2-11) (Table 1). Her morning plasma cortisol levels were not elevated, but did not suppress during a high-dose $4 \mathrm{mg}$ i.v. dexamethasone suppression test (Fig. 1). Abdominal CT scan confirmed a $2.9 \times 3.7 \mathrm{~cm}$ adrenal lesion with density of 20 Hounsfield Units (HU).

\section{Investigation}

The patient was evaluated with in vivo sequential tests to identify the presence of aberrant adrenal hormone

Table 1 Cortisol diurnal rhythm and values of urinary free cortisol (UFC), salivary cortisol and ACTH during pregnancy and 1-month post-partum.

Diurnal rhythm of cortisol (nmol/L)
$08: 00 \mathrm{~h}$
23:00 h
$24 \mathrm{~h} \mathrm{UFC} \mathrm{(nmol/day)}$
ACTH (pmol/L)
Salivary cortisol (nmol/L)

\begin{tabular}{c}
\hline 25-week gestation \\
\hline 868 \\
905 \\
$787(\mathrm{NR}<500)^{*}$ \\
$4(\mathrm{NV}: 2-11)$ \\
\end{tabular}

\begin{tabular}{c}
\hline 31-week gestation \\
\\
$4338(\mathrm{NR}<500)$ \\
$5(\mathrm{NV}: 2-11)$ \\
$15.7(\mathrm{NV}<7)$ \\
\hline
\end{tabular}

1-month post-partum

*24-h urinary free cortisol were performed in different hospital laboratories during pregnancy and after delivery. NR, normal upper range of normal for non-pregnant woman are indicated in parenthesis. The $24 \mathrm{~h}$ UFC with the $<500 \mathrm{nmol} / \mathrm{day}$ upper limit of normal were done with immunoassay and the $24 \mathrm{~h}$ UFC with the $<120 \mathrm{nmol} /$ day upper limit of normal was done by GCMS; NV, normal value . 


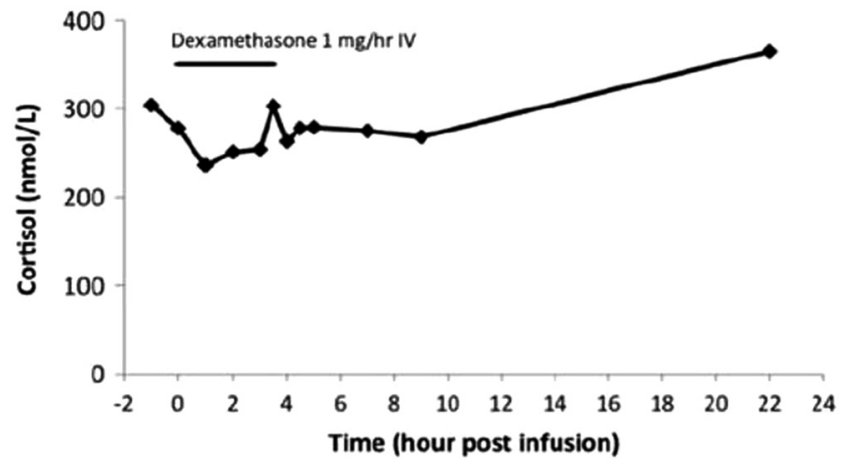

Figure 1

Cortisol variation during dexamethasone $1 \mathrm{mg} / \mathrm{h} \times 4 \mathrm{~h}$ infusion over a span of $24 \mathrm{~h}$.

receptors as previously described including an i.v. bolus of $300 \mathrm{IU}$ recombinant human LH (hLH) and 2 months later an $100 \mathrm{mcg}$ i.v. bolus of luteinising hormonereleasing hormone (LHRH) (3). in vivo screening tests to identify aberrant adrenal receptors (Fig. 2) showed a significant cortisol response (112\% increase) following administration of $250 \mathrm{mcg}$ of Cosyntropin i.v. and a partial response to vasopressin (Fig. 2B). There was no response

\section{A}

\begin{tabular}{lc|}
\hline Test & Cortisol (\%) \\
\hline Posture (Supine $\rightarrow$ Upright) & $+9.2 \%$ \\
Mixed Meal & $+2.8 \%$ \\
\hline ACTH (250 mcg IV) & $+112.5 \%$ \\
\hline Vasopressin (10 IU IM) & $+43.5 \%$ \\
\hline Metoclopramide (10 mg po) & $+0 \%$ \\
hLH (300 IU) & $-3.8 \%$ \\
\hline TRH (200mcg IV) & $-10 \%$ \\
\hline LHRH (100 mcg IV) & $+1 \%$ \\
\hline
\end{tabular}

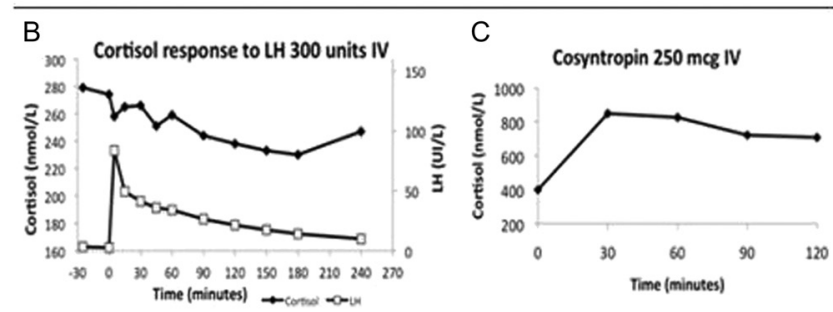

Figure 2

Serum cortisol response during various in vivo tests to identify aberrant hormone receptors. (Panel A) Cortisol response from baseline value to peak value (expressed in percentage increase) during in vivo testing to identify aberrant receptors. A partial response (25-49\%) was obtained with vasopressin and a positive response (>50\%) was only obtained in response to $\mathrm{ACTH}$ stimulation. *ACTH levels did not change during vasopressin test. (Panel B) Serum cortisol response following i.v. bolus administration of recombinant human LH. (Panel C) Cortisol response following 250 mcg Cosyntropin 1-24 intravenously. to administration of recombinant human LH (Fig. 2C), LHRH, metoclopramide and TRH, to upright posture or mixed meal (Fig. 2A). To evaluate the expression of ACTH receptors (MC2R), LHCG receptors (LHCGR) and GnRH receptor (GnRHR), total RNA was extracted from the patient's adenoma and compared to a pool of 11 normal adrenals (removed during radical nephrectomy) (NA pool). Quantitative RT-PCR analysis revealed detectable ACTH receptor (MC2R) mRNA levels, while LHCG receptor mRNA was almost undetectable (Fig. 3). GnRHR levels were similar to normal controls.

\section{Treatment}

Right adrenalectomy performed 7 months post-partum confirmed an adenoma (Weiss score: 0) with adjacent adrenal cortex atrophy.

\section{Outcome and follow-up}

She required glucocorticoid replacement post-operatively for 13 months. Normalisation of her HPA axis was documented by a $1 \mathrm{mcg}$ Cosyntropin stimulation test (cortisol increased to $500 \mathrm{nmol} / \mathrm{L}$ from $344 \mathrm{nmol} / \mathrm{L}$ baseline) and baseline ACTH level of $4.4 \mathrm{pmol} / \mathrm{L}$. Two years following adrenalectomy, she had a second pregnancy without diabetes, high blood pressure or CS. During her second pregnancy, LNSC measurements were less than $7 \mathrm{nmol} / \mathrm{L}$, UFC levels were between 38 and $114 \mathrm{nmol} /$ day (normal: $<120 \mathrm{nmol} / \mathrm{day}$ ) and plasma ACTH was between 4.0 and $4.5 \mathrm{pmol} / \mathrm{L}$.

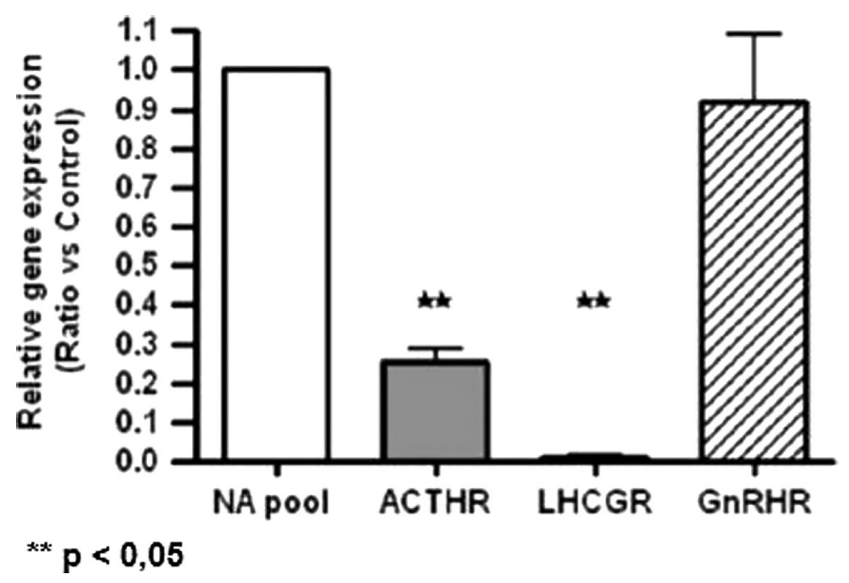

Figure 3

ACTH, LHCG and GnRH receptor mRNA expressions in the patient's adenoma compared to their expression in a pool of normal adrenals. 


\section{Discussion}

In some cases, pregnancy induces or exacerbates hypercortisolism, and the aberrant expression of $\mathrm{LH} /$ hCG receptors in adrenal tumours or BMAH tissue was one identified mechanism (3). We report here a case of CS associated with an adrenal adenoma that was greatly exacerbated during pregnancy possibly by a different placental-related peptide such as placental ACTH, placental $\mathrm{CRH}$ or CRH-like factor since hypercortisolism regressed considerably post-partum.

CS diagnosis during pregnancy is difficult due to physiological changes in cortisol regulation which occur during normal pregnancy. Total plasma cortisol levels increase progressively due to oestrogen-driven enhanced synthesis of cortisol-binding globulin in the liver (2). In addition, plasma and UFC increase progressively during pregnancy due to the upregulation of the HPA axis (2). In normal pregnancy, ACTH increases by 2- to 3-fold in the second trimester despite elevated levels of free cortisol suggesting that there is another source of ACTH distinct from the pituitary that is not subject to negative feedback by cortisol (2). The most useful tools to diagnose CS in the context of pregnancy are 3-fold elevation of UFC above the upper limit of normal and loss of diurnal variation of serum cortisol (2). Jung et al. established trimester-specific normal values for 24-h UFC measures by LC-MS/MS in 20 healthy pregnant patients compared to non-pregnant patients (4). The mean 24-h UFC in normal pregnancy was increased by 2 -fold and 3 -fold in the second and third trimester, respectively (4). The $1 \mathrm{mg}$ dexamethasone suppression test during pregnancy can be associated with false-positive results (2). Recently, Lopes et al. determined the best trimester-specific threshold for LNSC, based on sensitivity and specificity, to differentiate the normal pregnant women from non-pregnant CD: $7.0 \mathrm{nmol} / \mathrm{L}$ in the first trimester (sensitivity: $92 \%$ and specificity: 100\%), $7.2 \mathrm{nmol} / \mathrm{L}$ in the second trimester (sensitivity: $84 \%$ and specificity: $98 \%$ ) and $7.9 \mathrm{nmol} / \mathrm{L}$ in the last trimester (sensitivity: 80\% and specificity: 93\%) (5). Determining the aetiology of CS is also difficult during pregnancy since ACTH is only completely suppressed in half of the patients with primary adrenal aetiology of hypercortisolism (2). Our patient had a progressive increase in UFC value that reached more than 8-fold the upper limit of normal and a frankly elevated LNSC at 31 weeks of gestation. Her ACTH levels were not completely suppressed during pregnancy, despite a large excess of cortisol from her adrenal adenoma-causing severe CS.
In several cases of CS appearing or exacerbated during pregnancy, CS has improved or remitted after delivery and recurred in subsequent pregnancies (Table 2). In most cases, ACTH levels were suppressed (Table 2) suggesting that the stimulating factor bypassed the pituitary and stimulated the adrenal cortex directly. Several cases of pregnancyinduced CS associated with an in vivo stimulation of cortisol secretion by hCG were reported in the literature (Table 2). Most of these cases occurred with BMAH, but three cases of overt CS diagnosed during pregnancy were caused by an adrenal adenoma (6); in one, in vivo responses to hCG, LHRH, mixed meal, glucagon and vasopressin were demonstrated (6). The presence of LHCG receptor was demonstrated by immunohistochemistry (IHC) in the resected adrenal adenoma in two of these women (6). Recently, relapsing severe CS in two pregnancies was described in a woman with transient bilateral adrenal hyperplasia that remitted a few weeks after delivery (7); in vitro stimulation of cortisol production by $\mathrm{LH}$ and hCG was demonstrated in dispersed adrenal cells from this patient; the aberrant LHCGR remained expressed in BMAH cells after delivery which regressed in size between pregnancies (7). In other cases, in vitro studies by RT-PCR or IHC also showed an increased expression of LHCGR or GnRHR in BMAH (Table 2) (3).

Our patient's evolution suggests that a factor from the foeto-placental unit aggravated hypercortisolism during pregnancy. We suspected the expression of an aberrant GPCR expression such as LHCGR or GnRHR in the adrenal adenoma. However, in vivo, recombinant hLH or LHRH did not induce a cortisol response in this patient. In addition, LHCG receptor mRNA was almost undetectable, and GnRH receptor mRNA was similar to normal adrenal pool in RT-PCR of the patient's adrenal adenoma.

The only significant response during in vivo testing was to exogenous ACTH 1-24. As ACTH was not fully suppressed during pregnancy compared to the postpartum period despite a large exacerbation of the cortisol production by the adrenal adenoma, this suggests that circulating ACTH was of placental origin (pACTH) which is not regulated by glucocorticoid-negative feedback and is bioactive in vitro $(2,8)$. In two other cases of adrenal CS that were exacerbated during pregnancy and associated with non-suppressed ACTH, expression of ACTH receptor or the response to Cosyntropin 1-24 were not evaluated $(9,10)$. Most adrenal adenomas associated with mild or overt CS can respond to exogenous ACTH 1-24 (3) as they maintain functional ACTH receptors despite increased 


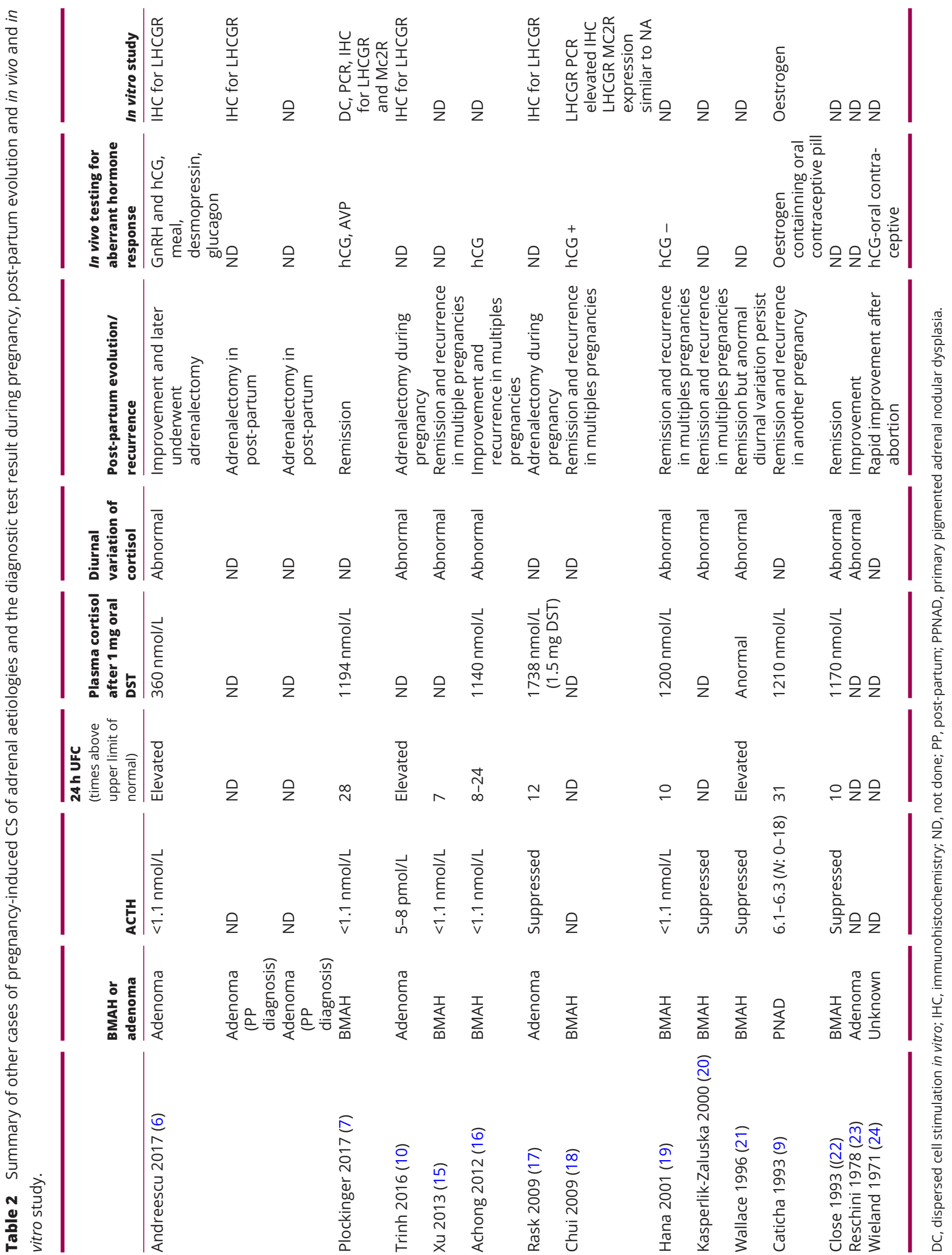


cortisol production and in most cases undetectable ACTH levels (11). Whereas adjacent normal adrenal tissue and contralateral adrenal cortex downregulate ACTH receptors, ACTH receptors can be upregulated in the adenoma (11). This patient's adenoma, resected during the post-partum period when overt CS had largely remitted, contained ACTH receptor mRNA, although levels were not as high as in the normal adrenal controls. Reincke et al. have demonstrated previously that some adrenocortical adenoma associated with mild CS express levels of ACTH-R mRNA lower than normal adrenal and that steroidogenic activity, measured by the expression of P450scc mRNA, correlates with the level of ACTH-R mRNA in the same tumour (12). Therefore, it is plausible to suggest that if the adenoma was resected during the period of overt CS, the expression of ACTH-R mRNA could have been higher. We suggest that pACTH or an ACTH-like substance stimulated the adenoma during pregnancy causing florid CS which regressed in the postpartum when ACTH levels became undetectable.

We cannot rule out the contribution of another factor derived from the foeto-placental unit such as $\mathrm{CRH}$ or a CRH-like substance that may have stimulated the cortisolsecreting adenoma directly (13). Placental CRH (pCRH) increases by a thousand-fold during pregnancy and was demonstrated to stimulate the secretion of peptides containing the ACTH sequence in primary culture of human placental cells (8). It potentially stimulates the HPA axis, although its biological activity is significantly limited by CRH-binding protein (2). It is impossible to rule out an effect from increasing oestrogen levels, which was previously shown to exacerbate CS in a woman with primary adrenal nodular dysplasia (PPNAD) during oral contraceptive use or pregnancy (9). IGF-2 secreted by the placenta could also have potentially contributed to the increased steroidogenesis through upregulation of steroidogenic key enzymes and ACTH receptor, but we did not determine IGF-2 or its receptor expression in this adenoma (14).

In conclusion, this case suggests a new regulatory mechanism underlying exacerbation of CS during pregnancy; while some cases of adrenal lesions with CS exacerbation during pregnancy were secondary to aberrant adrenal LHCGR expression, we propose that the normal MC2R present in cortisol-producing adenomas can be stimulated by the physiological second trimester increase in pACTH. Due to the lack of specific pharmacological inhibitor of pACTH, we cannot exclude that other placental-derived hormones other than hCG could have also contributed to CS exacerbation during pregnancy.

\section{Declaration of interest}

Isabelle Bourdeau is a Senior Editor of Endocrinology, Diabetes and Metabolism Case Reports. Isabelle Bourdeau was not involved in the review or editorial process for this paper, on which she is listed as an author. The other authors have nothing to declare.

\section{Funding}

This research did not receive any specific grant from any funding agency in the public, commercial or not-for-profit sector.

\section{Patient consent}

Written consent was obtained from the patient for the publication of this report.

\section{Author contribution statement}

I B supervised the in vitro studies. A L is responsible for the in vivo and in vitro investigations and the medical care of the patient. All authors revised and approved the manuscript.

\section{Acknowledgements}

The authors wish to thank Dr Robert Benoit from McGill University Health Center (MUHC) for initial investigation and referral of the patient and recognise the late Sylvie Oble for her expert contributions to determinations of RT-PCR studies of hormone receptors in adrenal tissues.

\section{References}

1 Caimari F, Valassi E, Garbayo P, Steffensen C, Santos A, Corcoy R \& Webb SM. Cushing's syndrome and pregnancy outcomes: a systematic review of published cases. Endocrine $2017 \mathbf{5 5} 555-563$. (https://doi.org/10.1007/s12020-016-1117-0)

2 Lindsay JR \& Nieman LK. The hypothalamic-pituitary-adrenal axis in pregnancy: challenges in disease detection and treatment. Endocrine Reviews 200526 775-799. (https://doi.org/10.1210/er.2004-0025)

3 St-Jean M, El Ghorayeb N, Bourdeau I \& Lacroix A. Aberrant G-protein coupled hormone receptor in adrenal diseases. Best Practice and Research: Clinical Endocrinology and Metabolism 201832 165-187. (https://doi.org/10.1016/j.beem.2018.01.003)

4 Jung C, Ho JT, Torpy DJ, Rogers A, Doogue M, Lewis JG, Czajko RJ \& Inder WJ. A longitudinal study of plasma and urinary cortisol in pregnancy and postpartum. Journal of Clinical Endocrinology and Metabolism 201196 1533-1540. doi:10.1210/jc.2010-2395.

5 Lopes LML, Francisco RPV, Galletta MAK \& Bronstein MD. Determination of nighttime salivary cortisol during pregnancy: comparison with values in non-pregnancy and Cushing's disease. Pituitary 201619 30-38. (https://doi.org/10.1007/s11102-015-0680-3)

6 Andreescu CE, Alwani RA, Hofland J, Looijenga LHJ, de Herder WW, Hofland LJ \& Feelders RA. Adrenal Cushing's syndrome during pregnancy. European Journal of Endocrinology 2017177 K13-K20. (https://doi.org/10.1530/EJE-17-0263) 
7 Plockinger U, Chrusciel M, Doroszko M, Saeger W, Blankenstein O, Kroiss M, Hauptmann K, Radke C, Tiling N, Huhtaniemi I, et al. Functional implications of $\mathrm{LH} / \mathrm{hCG}$ receptors in pregnancy-induced cushing syndrome. Journal of the Endocrine Society 20171 57-71. (https://doi.org/10.1210/js.2016-1021)

8 Petraglia F, Sawchenko PE, Rivier J \& Vale W. Evidence for local stimulation of ACTH secretion by corticotropin-releasing factor in human placenta. Nature 1987328 717-719. (https://doi. org $/ 10.1038 / 328717 \mathrm{a} 0$ )

9 Caticha O, Barrow R, Lamothe J, Odell D, Wilson DE \& Swislocki LM. Estradiol stimulates cortisol production by adrenal cells in estrogendependent primary adrenocortical nodular dysplasia. Journal of Clinical Endocrinology and Metabolism 199377 494-497. (https://doi. org/10.1210/jcem.77.2.8345057)

10 Trinh A, Chan I, Alexiadis M, Pell M, Kumar B \& Fuller PJ. Adrenal Cushing's syndrome in pregnancy: clinical and molecular characterisation of a case. Obstetric Medicine 20169 43-45. (https:// doi.org/10.1177/1753495X15618542)

11 Imai T, Sarkar D, Shibata A, Funahashi H, Morita-Matsuyama T, Kikumori T, Ohmori S \& Seo H. Expression of adrenocorticotropin receptor gene in adrenocortical adenomas from patients with Cushing syndrome: possible contribution for the autonomous production of cortisol. Annals of Surgery 2001234 85-91. (https:// doi.org/10.1097/00000658-200107000-00013)

12 Reincke M, Beuschlein F, Latronico AC, Arlt W, Chrousos GP \& Allolio B. Expression of adrenocorticotrophic hormone receptor mRNA in human adrenocortical neoplasms: correlation with P450scc expression. Clinical Endocrinology 199746 619-626. (https://doi. org/10.1046/j.1365-2265.1997.1991009.x)

13 Kageyama K, Hanada K \& Suda T. Differential regulation and roles of urocortins in human adrenal H295R cells. Regulatory Peptides 2010 162 18-25. (https://doi.org/10.1016/j.regpep.2010.02.006)

14 Altieri B, Tirabassi G, Casa S Della, Ronchi CL, Balercia G, Orio F, Pontecorvi A, Colao A \& Muscogiuri G. Adrenocortical tumors and insulin resistance: what is the first step? International Journal of Cancer. 20162794 2785-2794. (https://doi.org/10.1002/ ijc.29950)

15 Xu J, Wang Y, Shan L, Gu W \& Zeng W. Recurrent ACTHindependent Cushing's syndrome in multiple pregnancies.
Gynecological Endocrinology 201329 309-310. (https://doi.org/10. 3109/09513590.2012.743014)

16 Achong N, D'Emden M, Fagermo N \& Mortimer R. Pregnancyinduced Cushing's syndrome in recurrent pregnancies: case report and literature review. Australian and New Zealand Journal of Obstetrics and Gynaecology 201252 96-100. (https://doi.org/10.1111/j.1479828X.2011.01388.x)

17 Rask E, Schvarcz E, Hellman P, Hennings J, Karlsson FA \& Rao CV. Adrenocorticotropin-independent Cushing's syndrome in hormone/ human chorionic gonadotropin receptors. Journal of Endocrinological Investigation 200932 313-316. (https://doi.org/10.1007/BF03345718)

18 Chui MH, Özbey NC, Ezzat S, Kapran Y, Erbil Y, Asa SL \& Asa SL. Case report: adrenal LH/hCG receptor overexpression and gene amplification causing pregnancy-induced Cushing's syndrome. Endocrine Pathology 200920 256-261. (https://doi.org/10.1007/ s12022-009-9090-2)

19 Hána V, Dokoupilová M, Marek J \& Plavka R. Recurrent ACTHindependent Cushing's syndrome in multiple pregnancies and its treatment with metyrapone. Clinical Endocrinology 200154 277-281.

20 Kasperlik-zaluska AA, Szczupacka I, Leszczynska-Bystrzanowsk J \& Drus-Przybyszewska G. Pregnancy-dependent Cushing's syndrome in three pregnancies. British Journal of Obstetrics and Gynaecology 2000 107 810-812. (https://doi.org/10.1111/j.1471-0528.2000.tb13348.x)

21 Wallace C, Toth EL, Lewanczuk RZ \& Siminoski K. Pregnancyinduced Cushing's syndrome in multiple pregnancies. Journal of Clinical Endocrinology and Metabolism 199681 15-21. (https://doi. org/ 10.1210/jcem.81.1.8550743)

22 Close CF, Mann MC, Watts JF \& Taylor KG. ACTH-independent Cushing's syndrome in pregnancy with spontaneous resolution after delivery: Control of the hypercortisolism with metyrapone. Clinical Endocrinology 199339 375-379. (https://doi. org/10.1111/j.1365-2265.1993.tb02380.x)

23 Reschini E, Giustina G, Crosignani PG \& D'Alberton A. Spontaneous remission of Cushing syndrome after termination of pregnancy. Obstetrics and Gynecology 197851 598-602. (https://doi. org/10.1097/00006250-197805000-00019)

24 Wieland RG, Shaffer MB \& Glove RP. Cushing's syndrome complicating pregnancy; a case report. Obstetrics and Gynecology 1971 38 841-843.

Received in final form 16 November 2018 Accepted 16 January 2019 